\title{
PERBANDINGAN PENGUMPULAN ZAKAT PADA BAZNAS KABUPATEN TANAH DATAR SEBELUM DAN SETELAH IMPLEMENTASI PERATURAN BAZNAS NOMOR 2 TAHUN 2016
}

\section{THE COMPARATIVE STUDY OF ZAKAT COLLECTION IN BAZNAS TANAH DATAR REGENCY BEFORE AND AFTER THE IMPLEMENTATION OF BAZNAS REGULATION NUMBER 2, 2016}

\author{
Widi Nopiardo \\ Fakultas Ekonomi dan Bisnis Islam IAIN Batusangar \\ Jl. Sudirman No. 137, Kuburajo, Lima Kaum, Batusangkar \\ widinopiardo@iainbatusangkar.ac.id
}

Naskah diterima 16 Juni 2019, di-review 27 Juni 2019, disetujui 29 Juni 2019

\begin{abstract}
This study aims to compare the collection of zakat in BAZNAS Tanah Datar Regency before and after the implementation of BAZNAS Regulation Number 2, 2016 particularly on the Establishment and Work Procedures of the Zakat Collection Unit. The type of research is field research by using qualitative method. The place of research is in BAZNAZ, Tanah Datar Regency. Interviews and documentation were used as the technique of collecting data. The data were analyzed qualitatively. The finding reflects there was a significant decrease in the amount of zakat collection at BAZNAS in Tanah Datar Regency from 2016 to 2018, after the implementation of BAZNAS Regulation No. 2, 2016. The amount of zakat collection in 2016 was Rp. 9,687,841,423-. Meanwhile the amount of zakat collection in 2017 was Rp. 8,672,514,884-. It means the decline percentage from 2016 to 2017 was 10.48\%. Whereas in 2018, the amount of zakat collection was also declined to Rp. 7,311,597,007,- with the decline percentage 15.69\% from 2017.
\end{abstract}

Keywords: Zakat Collection, Implementation, BAZNAS Regulation No. 2 of 2016

\begin{abstract}
Abstrak: Penelitian ini bertujuan untuk membandingkan pengumpulan zakat pada BAZNAS Kabupaten Tanah Datar sebelum dan setelah implementasi Peraturan BAZNAS Nomor 2 Tahun 2016 Tentang Pembentukan dan tata Kerja Unit Pengumpul Zakat. Jenis penelitian ini adalah field research (penelitian lapangan) dengan menggunakan metode kualitatif. Tempat penelitian di BAZNAS Kabupaten Tanah Datar Teknik pengumpulan data menggunakan wawancara dan dokumentasi. Data yang telah dikumpulkan dianalisis secara kualitatif. Dari penelitian yang dilakukan dapat dinyatakan bahwa setelah diterapkannya Peraturan BAZNAS Nomor 2 tahun 2016 Tentang Pembentukan dan Tata Kerja Unit Pengumpul Zakat maka terjadi penurunan yang signifikan terhadap jumlah pengumpulan zakat di BAZNAS Kabupaten Tanah Datar. Jumlah pengumpulan zakat pada tahun 2016 sebesar Rp. 9.687.841.423,-, tahun 2017 Rp. 8.672.514.884,-, sedangkan pada tahun 2018 Rp. 7.311.597.007,-Dengan demikian tergambar bahwa dari tahun 2016 hingga tahun 2018 pengumpulan zakat cenderung mengalami penurunan. Pada tahun 2017, walaupun secara tegas belum diimplementasikan peraturan tersebut namun sudah terjadi terjadi penurunan sebesar 10,48 \% dari tahun 2016. Sedangkan pada tahun 2018 terjadi penurunan 15,69 \% dari tahun 2017.
\end{abstract}

Kata Kunci: Pengumpulan zakat, Implementasi, Peraturan BAZNAS No. 2 Tahun 2016

\section{PENDAHULUAN}

F undraising zakat merupakan kegiatan penting pada Organisasi Pengelola Zakat (OPZ) baikBAZNAS maupun LAZ. Fundraisingyang baik akan memaksimalkan jumlah penghimpunan dana zakat. Sebaliknya fundraising yang kurang maksimal akan berdampak pada pengurangan jumlah pengumpulan dana zakat. Fundraising 
zakat perlu dirancang untuk meningkatkan jumlah penghimpunan zakat. Dengan zakat yang terkumpul maka program pendistribusian zakat dapat dilaksanakan. Ketika dana zakat yang terkumpul kecil maka akan berpengaruh terhadap inovasi pendistribusian zakat. Jumlah penghimpunan yang kecil tentu akan linear dengan jumlah mustahik yang akan dibantu atau linear dengan program yang akan dilaksanakan. Artinya, penghimpunan zakat yang kecil atau sedikit berpotensi mengurangi jumlah mustahik yang akan dibantu atau mengurangi jumlah zakat yang akan didistribusian. Penghimpunan yang kecil juga akan membuat pengurus zakat tidak bisa menjalankan seluruh program yang direncanakan dengan optimal.

Fundraising merupakan kegiatan yang sangat penting bagi lembaga/ organisasi sosial dalam upaya mendukung jalannya program dan jalannya roda operasional agar lembaga/ organisasi sosial tersebut dapat mencapai maksud dan tujuan yang telah digariskan. Begitu penting peran fundraising itu sendiri dapat dikatakan sebagai faktor pendukung lembaga dalam pelaksanaan program-program atau operasional lembaga. Dengan demikian kegiatan fundraising diharapkan dapat meningkatkan jumlah pengumpulan zakat dari waktu ke waktu agar program atau operasional lembaga terlaksana dengan baik.

Semakin besar dana zakat yang berhasil dihimpun, semakin besar pula kemampuan OPZ untuk melakukan pengelolaan zakat secara profesional dan transparan sehingga kredibilitas mereka semakin tinggi. Dengan demikian, proses ini menjadi self-reinforcing. (Wibisono, 2015: 62)
Dengan citra yang baik yang tercermin dari profesionalisme dan transparansi akan menggiring publik bersedia menyalurkan dana zakatnya melalui Organisasi Pengelola Zakat (OPZ). Tidak mungkin citra terpancar dengan indahnya, tanpa diikuti ikhtiar membangun kapasitas, kapabilitas, dan kompetensi OPZ. Kepercayaan masyarakat lahir dari kapasitas, kapabilitas, dan kompetensi konkret lembaga. (Erlangga, 2012: t.h.)

Besaratau kecilnyajumlah zakatyang terkumpul dari aktifitas fundraising tergantung kepada amil zakat dalam mengelola sasaran pengumpulan zakat.

Amil zakat adalah petugas yang ditunjuk oleh pemerintah atau masyarakat untuk mengumpulkan zakat, menyimpan, kemudian membagi-bagikannya kepada yang berhak menerimanya (mustahik) (Hasan, 2015, 96). Salah satu tugas amil yaitu pengumpulan zakat, amil yang mempunyai tupoksi untuk mengumpulkan zakat bisa disebut fundraiser zakat.

Dalam pelaksanaan tugasnya fundraiser zakat membutuhkan informasi yang komprehensif, meliputi lingkup kewenangan pengumpulan, tata cara, dan ketentuan lain terkait pengumpulan. Untuk itu dibutuhkan payung hukum yang mengakomodir pengelolaan zakat pada umumnya, fundraising zakat pada khususnya.

Payung hukum ini tidak terlepas dari peranan pemerintah sebagai regulator, motivator, fasilitator, dan koordinator sehingga keberadaan OPZ dapat berjalan sesuai dengan yang diharapkan. (Karim, 2011: 95)

Harapan pengumpulan zakat yang meningkat dari tahun ke tahun ada pada fundraiser zakat. Oleh karena itu fundraiser zakat harus memahami 
peraturan demi peraturan yang ada sehingga mampu mengatasi kendala di lapangan, demi terwujudnya akselerasi pengumpulan zakat yang optimal. Dengan demikian diharapkan tercipta iklim fundraising zakat yang baik.

Setelah munculnya Undang-undang Nomor 23 Tahun 2011 Tentang Pengelolaan Zakat, maka lahirlah sejumlah peraturan-peraturan tentang Pengelolaan Zakat diantaranya Peraturan Pemerintah Nomor 14 Tahun 2014 Tentang Pelaksanaan Undang-undang Nomor 23 Tahun 2011 Tentang Pengelolaan Zakat, hingga Peraturan BAZNAS Nomor 2 Tahun 2016 Tentang Pembentukan dan Tata Kerja Unit Pengumpul Zakat.

Walaupun peraturan Perundang-undangan tersebut tidak secara eksplisit menjelaskan tentang Penghimpunan Zakat namun ada poinpoin yang mengatur hal-hal yang berkaitan dengan pengumpulan zakat. Salah satunya dapat dilihat pada Peraturan BAZNAS Nomor 2 Tahun 2016 Tentang Pembentukan dan Tata Kerja Unit Pengumpul Zakat, dalam materi peraturannya memuat lingkup kewenangan dari masing-masing BAZNAS, yaitu kewenangan BAZNAS Pusat, BAZNAS Propinsi, dan BAZNAS Kabupaten/ Kota.

Diterapkannya Peraturan BAZNAS Nomor 2 Tahun 2016 Tentang Pembentukan dan Tata Kerja Unit Pengumpul Zakat tentu menimbulkan polemik antara BAZNAS Kabupaten/ Kota dengan BAZNAS Propinsi. Di satu sisi adanya potensi pengurangan jumlah pengumpulan zakat pada BAZNAS Kabupaten/ Kota, namun di sisi lain ada potensi peningkatan jumlah pengumpulan zakat pada BAZNAS Propinsi. Hal ini disebabkan oleh adanya pengalihan lingkup kewenangan BAZNAS Kabupaten/ Kota ke BAZNAS Propinsi. Semula Muzaki dari PNS instansi SMA/ MA dan Perguruan Tinggi berzakat ke BAZNAS Kabupaten Kota namun dengan implementasi peraturan tersebut tentu akan mengurangi jumlah pengumpulan BAZNAS Kabupaten/ Kota

Hal tersebutlah yang dialami oleh salah satu BAZNAS di Indonesia di tingkat Kabupaten Kota, yaitu BAZNAS Kabupaten Tanah Datar. Pengalihan penyetoran zakat dari instansi SMA/ MA dan Perguruan Tinggi (IAIN Batusangkar) ke BAZNAS Propinsi Sumatera Barat menyebabkan penurunan jumlah pengumpulan zakat di BAZNAS Kabupaten Tanah Datar. Oleh karena itu penulis tertarik untuk menelaah lebih lanjut tentang perbandingan jumlah pengumpulan zakat di BAZNAS Kabupaten Tanah Datar sebelum dan setelah diterapkannya Peraturan BAZNAS Nomor 2 Tahun 2016 Tentang Pembentukan dan Tata Kerja Unit Pengumpul Zakat.

\section{Kerangka Konseptual}

\section{Pengertian Fundraising Zakat}

Fundraising adalah ruh dari Organisasi Pengelola Zakat (OPZ), karenanya OPZ tidak akan berhasil bila ia tidak memiliki strategi fundraising yang mumpuni. Fundraising dapat diartikan sebagai kegiatan dalam rangka menghimpun atau menggalang dana zakat, infak, dan sedekah serta sumber daya lainnya dari masyarakat (baik individu, kelompok, organisasi, dan perusahaan), yang akan disalurkan dan didayagunakan untuk mustahik. (Sani, 2010: 12) 
Fundraising zakat merupakan proses untuk mempengaruhi, membujuk, atau memersuasi masyarakat atau muzaki sehingga menimbulkan kesadaran, kepedulian, dan motivasi untuk menyerahkan zakatnya melalui amil pada Organisasi Pengelola Zakat (OPZ). (Nopiardo, 2017: 61)

\section{Jalur Penerimaan Zakat}

Sebelum diterima zakat melalui beberapa jalur, maka OPZ menyiapkan rekening zakat untuk menampung dana zakat yang berhasil dikumpulkan dari beberapa jalur penerimaan dana zakat.

1. Penerimaan zakat melalui Sekretariat BAZNAS.

2. Penerimaan zakat melalui Unit Pengumpul Zakat (UPZ).

3. Penerimaan zakatmelalui Kounter Penerimaan Zakat.

4. Penerimaanzakatmelaluiaplikasi pengumpulan zakat.

\section{Tujuan Pengumpulan Zakat}

1. Menghimpun zakat dari muzaki.

2. Meningkatkan jumlah muzaki.

3. Meningkatkan kepuasan muzaki.

4. Membangun, mempertahankan, dan meningkatkan citra lembaga.

5. Menghimpun simpatisan, relasi, dan sukarelawan zakat. (Nopiardo, 2017: 61-62)

\section{Lingkup Kewenangan Pengumpulan Zakat pada BAZNAS Berdasarkan Tingkatannya}

Lingkup kewenangan pengumpulan zakat tertuang pada BAB VI pasal 53 s.d. 54 Peraturan Pemerintah Nomor 14 Tahun 2014 Tentang Pelaksanaan Undang-undang Nomor 23 Tahun 2011 Tentang Pengelolaan Zakat, yaitu:

66 | Widi Nopiardo
Pasal 53 menerangkan bahwa:

1. BAZNAS berwenang melakukan pengumpulan zakat melalui UPZ dan/atau secara langsung.

2. Pengumpulan zakat melalui UPZ sebagaimana dimaksud pada ayat (1) dilakukan dengan cara membentuk UPZ pada:
a. Lembaga negara;
b. Kementerian/ lembaga pemerintah non kementerian;
c. Badan Usaha Milik Negara;
d. Perusahaan swasta nasional dan asing;
e. Perwakilan Republik Indonesia di luar negeri;
f. Kantor-kantor perwakilan negara asing/ lembaga asing; dan
g. Masjid negara.

3. Pengumpulan zakat secara langsung sebagaimana dimaksud pada ayat (1) dilakukan melalui sarana yang telah disediakan oleh BAZNAS.

Dalam Pasal 54 dinyatakan bahwa:

1. BAZNAS provinsi berwenang melakukan pengumpulan zakat melalui UPZ dan/atau secara langsung.

2. Pengumpulan zakat melalui UPZ sebagaimana dimaksud pada ayat (1) dilakukan dengan cara membentuk UPZ pada:
a. Kantor instansi vertikal;
b. Kantor Satuan Kerja Perangkat Daerah/ lembaga daerah provinsi;
c. Badan Usaha Milik Daerah provinsi;
d. Perusahaan swasta skala provinsi;
e. Perguruan tinggi; dan
f. Masjid raya. 
3. Pengumpulan zakat secara langsung sebagaimana dimaksud pada ayat (1) dilakukan melalui sarana yang telah disediakan oleh BAZNAS provinsi.

Sedangkan pada Pasal 55 dijelaskan tentang:

1. BAZNAS kabupaten/ kota berwenang melakukan pengumpulan zakat melalui UPZ dan/atau secara langsung.

2. Pengumpulan zakat melalui UPZ sebagaimana dimaksud pada ayat (1) dilakukan dengan cara membentuk UPZ pada:
a. Kantor Satuan Kerja Pemerintah Daerah/ lembaga daerah kabupaten/ kota;
b. Kantor instansi vertikal tingkat kabupaten/ kota;
c. Badan Usaha Milik Daerah kabupaten/ kota;
d. Perusahaan swasta skala kabupaten/kota;
e. Masjid, mushalla, langgar, surau atau nama lainnya;
f. Sekolah/madrasah dan lembaga pendidikan lain;
g. Kecamatan atau nama lainnya; dan
h. Desa/kelurahan atau nama lainnya.

3. Pengumpulan zakat secara langsung sebagaimana dimaksud pada ayat (1) dilakukan melalui sarana yang telah disediakan oleh BAZNAS kabupaten/kota. (n.n., t.th.: 60-62)

\section{METODE PENELITIAN}

Penelitian ini bertujuan untuk membandingkan pengumpulan zakat pada BAZNAS Kabupaten Tanah Datar sebelum dan sesudah implementasi Peraturan BAZNAS Nomor 2 Tahun 2016 Tentang Pembentukan dan Tata Kerja Unit Pengumpul Zakat.
Oleh karena itu dibutuhkan metode penelitian yang diuraikan sebagai berikut:

\section{Jenis Penelitian}

Jenis penelitian ini adalah field research, yakni semua data penelitian didapatkan di lapangan, dengan metode kualitatif deskriptif.

Penelitian ini menggunakan pendekatan kualitatif deskriptif, yaitu penelitian yang menggambarkan atau melukiskan objek penelitian berdasarkan fakta-fakta yang tampak atau sebagaimana adanya (Nawawi dan Mertini, 1996: 73).

Selanjutnya Sugiyono (2011: 11) berpendapat bahwa pada penelitian kualitatif, teori diartikan sebagai paradigma. Penelitian kualitatif bertujuan untuk mengungkapkan informasi kualitatif sehingga lebih menekankan pada masalah proses dan makna dengan cara mendeskripsikan sesuatu masalah.

Metode kualitatif digunakan untuk mendapatkan data yang mendalam, suatu data yang mengandung makna. Makna adalah data yang sebenarnya, data yang pasti yang merupakan suatu nilai di balik data yang tampak. (Sugiyono, 2018: 18-19). Metode ini digunakan untuk mendapatkan makna dari perbandingan jumlah pengumpulan zakat sebelum dan setelah Peraturan BAZNAS Nomor 2 Tahun 2016 Tentang Pembentukan dan Tata Kerja Unit Pengumpul Zakat.

\section{Tempat dan Waktu Penelitian}

Penelitian ini di Kantor BAZNAS Kabupaten Tanah Datar yang beralamat di Kompleks Islamic Centre Pagaruyung Kabupaten Tanah Datar. 
Waktu pengumpulan data penelitian dari Bulan Agustus 2018 s.d. Februari 2019.

\section{Jenis dan Sumber Data}

Jenis data yang dikumpulkan berupa data kualitatif (rekapitulasi pengumpulan zakat dari 2016-2018 dan penjelasan kualitatif dari data tersebut sehingga diperoleh makna dari data dimaksud). Sumber data primer dalam penelitian ini adalah Dokumen BAZNAS Kabupaten Tanah Datar.

\section{Teknik Pengumpulan Data}

Untuk mengumpulkan data digunakan beberapa teknik yaitu wawancara untuk memperkuat analisis dari data kualitatif. Untuk menguatkan data dari wawancara ini, dilakukan dokumentasi untuk memperoleh data langsung dari tempat penelitian, meliputi buku-buku yang relevan, peraturan-peraturan, laporan kegiatan, laporan keuangan, foto-foto, film dokumen, data yang relevan untuk penelitian (Riduan, 2005: 76). Data dari dokumentasi berupa data rekap pengumpulan zakat dari tahun 2016-2018 dan rekap pendistribusian zakat.

\section{Teknik Analisis Data}

Data yang telah dikumpulkan dianalisis secara kualitatif dengan mendeskripsikan hasil wawancara dan dokumen rekapitulasi dan persentasenya kenaikan atau penurunannya. Data diklasifikasikan untuk memudahkan dalam menyaring mana data yang dibutuhkan atau tidak. Setelah data dikelompokkan, data diformulasikan dalam tabel persentase, bentuk teks, agar lebih dimengerti, setelah itu ditarik kesimpulan dari data tersebut sehingga dapat menjawab masalah penelitian.

\section{PEMBAHASAN DAN HASIL}

Jumlah pengumpulan zakat tahun 2016 sebelum implementasi Peraturan BAZNAS Nomor 2 Tahun 2016 Tentang Pembentukan dan Tata Kerja Unit Pengumpul Zakat, pengumpulan zakat pada BAZNAS Kabupaten Tanah Datar tergambar sebagai berikut:

Tabel 1. Jumlah Pengumpulan Zakat Tahun 2016 pada BAZNAS Kabupaten Tanah Datar

\begin{tabular}{|l|l|r|c|}
\hline \multirow{2}{*}{ No } & \multicolumn{1}{|c|}{ Ket/ Bulan } & Jumlah (Rp.) & Total (Rp.) \\
\cline { 2 - 4 } & Saldo Tahun 2015 & & $\mathbf{1 . 4 6 0 . 4 5 6 . 9 3 5 , -}$ \\
\hline 1 & Januari & $735.305 .987,-$ & \\
\hline 2 & Februari & $799.171 .324,-$ & \\
\hline 3 & Maret & $746.391 .034,-$ & \\
\hline 4 & April & $806.403 .108,-$ & \\
\hline 5 & Mei & $926.639 .752,-$ & \\
\hline 6 & Juni & $1.138 .009 .193,-$ & \\
\hline 7 & Juli & $714.294 .650,-$ & \\
\hline 8 & Agustus & $760.762 .640,-$ & \\
\hline 9 & September & $723.444 .811,-$ & \\
\hline 10 & Oktober & $826.214 .156,-$ & \\
\hline 11 & Nopember & $813.442 .374,-$ & \\
\hline 12 & Desember & $9.687 .841 .423,-$ \\
\hline Pengumpulan Tahun 2016 & $11.148 .298 .358,-$ \\
\hline $\begin{array}{l}|l| \\
\text { Saldo Tahun 2015 + Pengumpulan Tahun } \\
2016\end{array}$
\end{tabular}

Sumber : Diolah dari Dokumen BAZNAS Kabupaten Tanah Datar, 2016

Tabel 1 menyajikan jumlah pengumpulan zakat pada tahun 2016 dengan total pengumpulan Rp. 9.687.841.423,-. Jika total dana zakat yang terkumpul ditambah saldo tahun sebelumnya yaitu tahun 2015 berjumlah Rp. 1.460.456.935,hasilnya menjadi Rp. 11.148.298.358,-. Sedangkan total dana zakat yang terkumpul pada tahun 2017 yaitu sebagai berikut:

Tabel 2. Jumlah Pengumpulan Zakat Tahun 2017 pada BAZNAS Kabupaten Tanah Datar

\begin{tabular}{|l|l|c|c|}
\hline \multirow{2}{*}{ No } & \multicolumn{1}{|c|}{ Ket/ Bulan } & Jumlah (Rp.) & Total (Rp.) \\
\cline { 2 - 4 } & Saldo Tahun 2016 & & $\mathbf{2 . 0 6 9 . 1 8 5 . 0 7 1 , -}$ \\
\hline 1 & Januari & $621.343 .550,-$ & \\
\hline 2 & Februari & $637.737 .991,-$ & \\
\hline 3 & Maret & $685.182 .892,-$ & \\
\hline 4 & April & $639.724 .286,-$ & \\
\hline
\end{tabular}




\begin{tabular}{|l|l|r|r|}
\hline 5 & Mei & $583.852 .277,-$ & \\
\hline 6 & Juni & $1.043 .117 .652,-$ & \\
\hline 7 & Juli & $1.048 .706 .094,-$ & \\
\hline 8 & Agustus & $680.564 .416,-$ & \\
\hline 9 & September & $644.029 .486,-$ & \\
\hline 10 & Oktober & $645.808 .428,-$ & \\
\hline 11 & Nopember & $706.943 .930,-$ & \\
\hline 12 & Desember & $835.503 .882,-$ & \\
\hline \multicolumn{3}{|l|}{ Pengumpulan Tahun 2017 } & 10.672.514.884,- \\
\hline $\begin{array}{l}\text { Saldo Tahun 2016 + Pengumpulan Tahun } \\
2017\end{array}$ & $10.741 .693 .955,-$ \\
\hline
\end{tabular}

Sumber : Diolah dari Dokumen BAZNAS Kabupaten Tanah Datar, 2017

Tabel 2 menyajikan Jumlah pengumpulan zakat pada tahun 2017 dengan total pengumpulan Rp. 8.672.514.884,-. Jika total dana zakat yang terkumpul ditambah saldo tahun sebelumnya yaitu tahun 2016 berjumlah Rp. 2.069.185.071,hasilnya menjadi Rp. 10.741.693.955,-. Sedangkan total dana zakat yang terkumpul pada tahun 2018 yaitu sebagai berikut:

Tabel 3. Jumlah Pengumpulan Zakat Tahun 2018 pada BAZNAS Kabupaten Tanah Datar

\begin{tabular}{|l|l|c|c|}
\hline \multirow{2}{*}{ No } & \multicolumn{1}{|c|}{ Ket/ Bulan } & Jumlah (Rp.) & Total (Rp.) \\
\cline { 2 - 4 } & Saldo Tahun 2017 & & $\mathbf{2 . 8 8 1 . 6 9 2 . 9 3 7 , -}$ \\
\hline 1 & Januari & $602.877 .815,-$ & \\
\hline 2 & Februari & $543.618 .743,-$ & \\
\hline 3 & Maret & $571.905 .259,-$ & \\
\hline 4 & April & $542.172 .702,-$ & \\
\hline 5 & Mei & $548.626 .685,-$ & \\
\hline 6 & Juni & $804.300 .848,-$ & \\
\hline 7 & Juli & $858.561 .721,-$ & \\
\hline 8 & Agustus & $605.349 .900,-$ & \\
\hline 9 & September & $528.521 .898,-$ & \\
\hline 10 & Oktober & $497.237 .782,-$ & \\
\hline 11 & Nopember & $667.514 .341,-$ & \\
\hline 12 & Desember & $540.909 .313,-$ & \\
\hline Pengumpulan Tahun 2018 & $7.311 .597 .007,-$ \\
\hline \multicolumn{2}{|l|}{$\begin{array}{l}\text { Saldo Tahun 2017 + Pengumpulan Tahun } \\
2018\end{array}$} & $10.193 .289 .944,--$ \\
\hline
\end{tabular}

Sumber : Diolah dari Dokumen BAZNAS Kabupaten Tanah Datar, 2018

Tabel 3 menyajikan Jumlah pengumpulan zakat pada tahun 2018 dengan total pengumpulan Rp. 7.311.597.007,-. Jika total dana zakat yang terkumpul ditambah saldo tahun sebelumnya yaitu tahun 2017 berjumlah Rp. 2.881.692.937,hasilnya menjadi Rp. 10.193.289.944,-. Sedangkan Rekapitulasi dana zakat yang terkumpul dari tahun 2016 s.d. 2018 yaitu sebagai berikut:
Tabel 4. Rekapitulasi Pengumpulan Zakat pada BAZNAS Kabupaten Tanah Datar dari Tahun 2016 s.d. 2018

\begin{tabular}{|l|l|c|r|l|}
\hline No & Tahun & Total (Rp) & $\begin{array}{c}\text { Persentase } \\
\%\end{array}$ & Keterangan \\
\hline 1 & 2016 & $9.687 .841 .423,-$ & - \\
\hline 2 & 2017 & $8.672 .514 .884,-$ & $-10,48$ & Turun \\
\hline 3 & 2018 & $7.311 .597 .007,-$ & $-15,69$ & Turun \\
\hline
\end{tabular}

Sumber : Diolah dari Dokumen BAZNAS Kabupaten Tanah Datar

Dari rekapitulasi pengumpulan zakat di atas dapat dinyatakan bahwa dari tahun 2016 hingga tahun 2018 pengumpulan zakat cenderung mengalami penurunan. Pada tahun 2017 terjadi penurunan sebesar 10,48 \% dari tahun 2016. Sedangkan pada tahun 2018 terjadi penurunan $15,69 \%$ dari tahun 2017. Besaran pengumpulan zakat dapat dilihat pada diagram berikut:

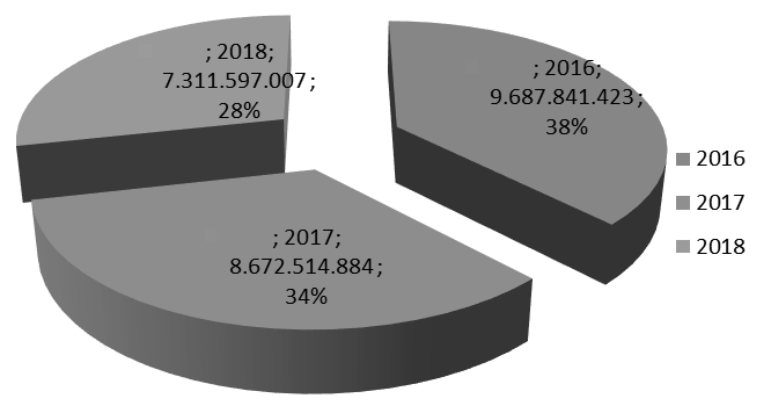

Sumber: Diolah dari Dokumen BAZNAS Kabupaten Tanah Datar

Gambar 1 Diagram Rekapitulasi Pengumpulan Zakat pada BAZNAS Kabupaten Tanah Datar dari Tahun 2016 s.d. 2018

Diagram di atas menjelaskan bahwa jumlah pengumpulan zakat pada tahun 2016 sebesar Rp. 9.687.841.423,-, tahun 2017 Rp. 8.672.514.884,-, sedangkan pada tahun 2018 Rp. 7.311.597.007,-. Berdasarkan informasi dari BAZNAS Kabupaten Tanah Datar (Riko Afrimaigus, Wawancara, 04 Agustus 2018) dan BAZNAS Propinsi Sumatera Barat (Astepenson, Wawancara, 11 September 2018) menyatakan bahwa implementasi 
Peraturan BAZNAS Nomor 2 Tahun 2016

Tentang Pembentukan dan tata Kerja Unit Pengumpul Zakat baru diterapkan pada tahun 2018, artinya BAZNAS Propinsi Sumatera Barat secara resmi menerima pengalihan kewenangan pengumpulan zakat dari BAZNAS Kabupaten/ Kota se-Sumatera Barat pada tahun 2018. Namun jika ditilik pada rekapitulasi pengumpulan zakat pada BAZNAS Kabupaten Tanah Datar penurunan jumlah pengumpulan zakat sudah terjadi di tahun 2017. Idealnya, setelah BAZNAS Propinsi Sumatera Barat menyanggupi untuk implementasi peraturan tersebut maka barulah terjadi penurunan pengumpulan zakat pada BAZNAS Kabupaten Tanah Datar.

Tabel 5. Perbandingan Pengumpulan Zakat pada BAZNAS Kabupaten Tanah Datar Sebelum dan Setelah Implementasi Peraturan BAZNAS Nomor 2 Tahun 2016 Tentang Pembentukan dan Tata Kerja Unit Pengumpul Zakat

\begin{tabular}{|c|c|c|c|c|}
\hline No & Tahun & $\begin{array}{l}\text { Sebelum/ Setelah } \\
\text { Implementasi }\end{array}$ & Total Pengumpulan & Keterangan \\
\hline 1 & 2016 & Sebelum Implementasi & $9.687 .841 .423,-$ & $\begin{array}{l}\text { SMA/ MA/ Perguruan Tinggi masih } \\
\text { menyetorkan zakat ke BAZNAS Kabupaten } \\
\text { Tanah Datar. }\end{array}$ \\
\hline 2 & 2017 & Sebelum Implementasi & $8.672 .514 .884,-$ & $\begin{array}{l}\text { Sehubungan belum adanya instruksi secara } \\
\text { tegas untuk mengimplementasikan peraturan } \\
\text { BAZNAS No. } 2 \text { Tahun } 2016 \text { kepada SMAI } \\
\text { MA/ dan Perguruan Tinggi (IAIN Batusangkar) } \\
\text { untuk menyetorkan zakat ke BAZNAS } \\
\text { Propinsi Sumatera Barat, sehingga sebagian } \\
\text { besar masih menyetorkan zakat ke BAZNAS } \\
\text { Kabupaten Tanah Datar. Sedangkan yang lain } \\
\text { ada yang masih ragu memaknai peraturan } \\
\text { tersebut sehingga tidak menyetorkan ke } \\
\text { BAZNAS Kabupaten Tanah Datar dan tidak } \\
\text { pula menyetorkan zakat ke BAZNAS Propinsi } \\
\text { Sumatera Barat }\end{array}$ \\
\hline 3 & 2018 & Setelah Implementasi & 7.311.597.007,- & $\begin{array}{l}\text { Sebagian besar SMA/ MA/ sudah menyetorkan } \\
\text { zakat ke BAZNAS Propinsi Sumatera Barat, } \\
\text { sementara Perguruan Tinggi (IAIN Batusangkar) } \\
\text { hanya bulan Januari } 2018 \text { menyetorkan } \\
\text { zakat ke BAZNAS Kabupaten Tanah Datar, } \\
\text { selebihnya dari Februari s.d. Desember } 2018 \\
\text { menyetorkan zakat ke BAZNAS Propinsi } \\
\text { Sumatera Barat. }\end{array}$ \\
\hline
\end{tabular}

Sumber : Diolah dari Dokumen BAZNAS Kabupaten Tanah Datar dan Wawancara

Dari keterangan tabel di atas dapat dikemukakan bahwa pada tahun 2016 atau sebelum implementasi Peraturan BAZNAS Nomor 2 Tahun 2016 Tentang Pembentukan dan Tata Kerja Unit Pengumpul Zakat terdapat pengumpulan zakat sebesar Rp. 9.687.841.423,-. Hal ini didukung oleh SMA/ MA/ Perguruan Tinggi masih menyetorkan zakat ke BAZNAS Kabupaten Tanah Datar. Namun di tahun 2017 terjadi penurunan sebesar 10,48 \% sehingga jumlah pengumpulan zakat sebesar Rp. 8.672.514.884,-. Menurut Riko Afrimaigus, hal ini ditengarai oleh belum adanya instruksi secara tegas untuk mengimplementasikan peraturan BAZNAS No. 2 Tahun 2016 kepada SMA/ MA/ dan Perguruan Tinggi (IAIN Batusangkar) untuk menyetorkan zakat ke BAZNAS Propinsi Sumatera Barat, sehingga sebagian besar masih menyetorkan zakat ke BAZNAS Kabupaten Tanah Datar dan ada yang masih ragu memaknai peraturan tersebut sehingga tidak menyetorkan ke BAZNAS Kabupaten Tanah Datar dan tidak pula menyetorkan zakat ke BAZNAS Propinsi Sumatera Barat. Penurunan

70 | Widi Nopiardo 
di tahun 2017 tidak terlalu drastis. Sementara di tahun 2018 terjadi penurunan dari tahun 2017 sebesar 15,69 \% sehingga jumlah pengumpulan menjadi Rp. 7.311.597.007,- Penurunan ini sejalan dengan dimulainya pemungutan zakat oleh BAZNAS Propinsi Sumatera Barat khususnya untuk SMA/ MA dan Perguruan Tinggi, yang sebelumnya menjadi kewenangan pengumpulan BAZNAS Kabupaten Tanah Datar.

Dengan demikian dapat dinyatakan bahwa implementasi Peraturan BAZNAS Nomor 2 Tahun 2016 Tentang Pembentukan dan tata Kerja Unit Pengumpul Zakat tidaklah langsung secara komprehensif di awal tahun 2017. Namun butuh penyesuaian sekitar satu tahun, sehingga barulah di tahun 2018 secara berangsur dapat diterapkan.

\section{PENUTUP}

Berdasarkan penelitian yang dilakukan dapat dikemukakan analisis bahwa setelah diterapkannya Peraturan BAZNAS Nomor 2 tahun 2016 Tentang Pembentukan dan Tata Kerja Unit Pengumpul Zakat maka terjadi penurunan yang signifikan terhadap jumlah pengumpulan zakat di BAZNAS Kabupaten Tanah Datar. Jumlah pengumpulan zakat pada tahun 2016 sebesar Rp. 9.687.841.423,-, tahun 2017 Rp. 8.672.514.884,-, sedangkan pada tahun 2018 Rp. 7.311.597.007,-. Dengan demikian tergambar bahwa dari tahun 2016 hingga tahun 2018 pengumpulan zakat cenderung mengalami penurunan. Pada tahun 2017, walaupun secara tegas belum diimplementasikan peraturan tersebut namun sudah terjadi terjadi penurunan sebesar 10,48 \% dari tahun 2016. Sedangkan pada tahun 2018 setelah diimplementasikannya peraturan tersebut terjadi penurunan 15,69 \% dari tahun 2017.

\section{DAFTAR KEPUSTAKAAN}

Afrimaigus, Riko. Wawancara, 04 Agustus 2018.

Astepenson. Wawancara, 11 September 2018.

Dokumen BAZNAS Kabupaten Tanah Datar

Erlangga, Yugha. 2012. Sebuah Apresiasi Sebuah Dedikasi: Program Zakat Terbaik. Ciputat. IMZ Publishing.

Hasan, M. Ali. 2015. Zakat dan Infak: Salah Satu Solusi Mengatasi Problema Sosial di Indonesia. Jakarta: Prenadamedia Group

Karim, Abdul. 2011. Zakat for Poverty Alleviation. Jakarta: Forum Zakat (FOZ) dan World Zakat Forum (WZF).

Nawawi, Hadari dan Mimi Martini. 1996. Penelitian Terapan. Yogyakarta: Gadjah Mada University Press.

N.n. t.th. Undang-undang Pengelolaan Zakat: Undang-undang Republik Indonesia Nomor 23 Tahun 2011 Tentang Pengelolaan Zakat, dilengkapi dengan Peraturan Pemerintah Republik Indonesia Nomor 14 Tahun 2014 Tentang Pelaksanaan Undang-undang Republik Indonesia Nomor 23 Tahun 2011 Tentang Pengelolaan Zakat. Yogyakarta: Pustaka Mahardika.

Nopiardo, Widi. 2017. Strategi Fundraising Dana Zakat pada BAZNAS Kabupaten Tanah Datar, Imara: Jurnal Riset Ekonomi Islam, Volume 1, Nomor 1, Desember 2017 
JURNAL IMARA

Riduwan. 2005. Belajar Mudah Penelitian untuk Guru, Karyawan, dan Peneliti Pemula, Bandung: ALFABETA

Sani, M. Anwar. 2010. Jurus Menghimpun Fulus: Manajemen Zakat Berbasis Masjid. Jakarta: PT Gramedia Pustaka Utama.

Sugiyono, 2011. Metode Penelitian Pendidikan: Pendekatan Kuantitatif, Kualitatif, dan R\&D. Bandung: Alfabeta.
Sugiyono. 2018. Metode Penelitian Kuantitatif. Bandung: CV Alfabeta.

Wibisono, Yusuf. 2015. Mengelola Zakat Indonesia: Diskursus Pengelolaan Zakat Nasional dari Rezim Undang-Undang Nomor 38 Tahun 1999 ke Rezim Undang-Undang Nomor 23 Tahun 2011. Jakarta: Prenadamedia Group.

72 | Widi Nopiardo 